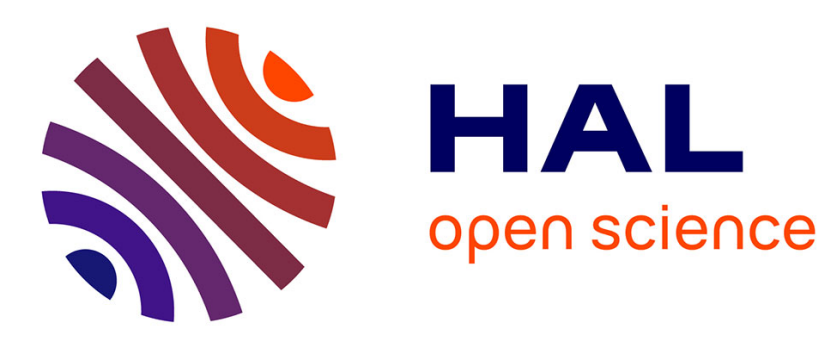

\title{
Do wild bees complement honeybee pollination of confection sunflowers in Israel?
}

Gideon Pisanty, Alexandra-Maria Klein, Yael Mandelik

\section{To cite this version:}

Gideon Pisanty, Alexandra-Maria Klein, Yael Mandelik. Do wild bees complement honeybee pollination of confection sunflowers in Israel?. Apidologie, 2014, 45 (2), pp.235-247. 10.1007/s13592-0130242-5 . hal-01234719

\author{
HAL Id: hal-01234719 \\ https://hal.science/hal-01234719
}

Submitted on 27 Nov 2015

HAL is a multi-disciplinary open access archive for the deposit and dissemination of scientific research documents, whether they are published or not. The documents may come from teaching and research institutions in France or abroad, or from public or private research centers.
L'archive ouverte pluridisciplinaire HAL, est destinée au dépôt et à la diffusion de documents scientifiques de niveau recherche, publiés ou non, émanant des établissements d'enseignement et de recherche français ou étrangers, des laboratoires publics ou privés. 


\title{
Do wild bees complement honeybee pollination of confection sunflowers in Israel?
}

\author{
Gideon Pisantr ${ }^{1}$, Alexandra-Maria KLeIN $^{2,3}$, Yael MandeliK ${ }^{1}$ \\ ${ }^{1}$ Department of Entomology, Robert H. Smith Faculty of Agriculture, Food and Environment, \\ The Hebrew University of Jerusalem, Rehovot, Israel \\ ${ }^{2}$ Institute of Ecology, Section Ecosystem Functions, Leuphana University of Lüneburg, Lüneburg, Germany \\ ${ }^{3}$ Faculty of Environment and Natural Resources, Institute of Earth and Environmental Sciences, \\ Chair of Nature Conservation and Landscape Ecology, University of Freiburg, Freiburg, Germany
}

Received 9 January 2013 - Revised 15 May 2013 - Accepted 13 September 2013

\begin{abstract}
Complementarity between species in the use of flower resources can enhance the pollination services of diverse pollinator communities. To test for complementarity, we studied fine-scale patterns of flower visitation and contribution to seed set of the three locally dominant bee species (commercially managed honeybees and two wild, non-managed Lasioglossum species) visiting confection (non-oil) sunflower in central Israel. The three species differed in their temporal (time of day) and phenological (head bloom stage) visitation patterns but generally showed niche redundancy. Moreover, honeybees strongly outperformed the wild species in both visitation rates and single-visit contributions to seed set. We conclude that the present communities and densities of wild bees do not complement honeybee sunflower pollination in the studied system. Sunflower seed production in central Israel is currently dependent solely upon the high stocking rate and pollination efficiency of honeybees.
\end{abstract}

\section{crop pollination / Lasioglossum malachurum / Lasioglossum politum / pollinator complementarity / intra-inflorescence variation}

\section{INTRODUCTION}

In recent years, there have been growing concerns about declines in populations of honeybees and wild pollinators (Biesmeijer et al. 2006; Holden 2006; Potts et al. 2010). At the same time, crop pollination shortages have become evident (Richards 2001; Potts et al.

Electronic supplementary material The online version of this article (doi:10.1007/s13592-013-0242-5) contains supplementary material, which is available to authorized users.

Corresponding author: G. Pisanty, gidpisa79@yahoo.com

Manuscript Editor: Yves Le Conte
2010; but see Aizen et al. 2008). Maintaining diverse communities of pollinators has been suggested as a potential solution, as differences between pollinator species in life history traits and environmental sensitivity may allow greater spatial and temporal stability in pollination services (Winfree and Kremen 2009; Garibaldi et al. 2011). Increased functional stability may provide a 'safety net' in cases of sudden collapses of commercial pollinator populations or major environmental changes (Winfree et al. 2007; Winfree and Kremen 2009). Furthermore, the combination of several pollinator species may increase crop yields compared to those obtained with a single commercial pollinator species, due to spatiotemporal and behavioural 
complementarity between pollinator species in their foraging activity (Hoehn et al. 2008; Blüthgen and Klein 2011; Brittain et al. 2012).

The potential of a diverse pollinator community to provide a pollination safety net and increase pollination levels depends on its ability to provide sufficient pollination services under a variety of environmental conditions (Kremen 2005). Most studies have examined the effects of relatively coarse spatiotemporal factors, such as landscapes, sites (fields) and seasons, on pollinators' activity and efficiency while compiling finer scale data, especially at the interand intra-plant level, such as size, location or phenological state of flowers or inflorescences. Only few studies have directly investigated how the visitation activity of commercial and unmanaged pollinators is affected by such fine-resolution spatiotemporal factors (e.g. flower height, Albrecht et al. 2012; location within a tree, Brittain et al. 2012). These studies are important for assessing the degree of functional resilience and niche complementarity in pollinator communities and eventually acquiring a more accurate estimation of ecosystems' potential for delivering pollination services (Kremen and Ostfeld 2005; Blüthgen and Klein 2011).

Architectural pollinator complementarity within plant individuals, i.e. the complementing tendencies of different pollinator species to visit and pollinate floral units located on different parts of a single plant, remains a poor, yet promising direction of study in an effort to better understand the role of complementarity in enhancing crop pollination (Blüthgen and Klein 2011). In particular, complementarity in the pollination of specific regions within a simple inflorescence bearing sexually similar, homostylous flowers (e.g. Asteraceae spp.) has scarcely been examined (but see Paton 1993; Chagnon et al. 1993). Plants bearing inflorescences often show morphological, phenological and/or physiological variation between flowers within an inflorescence, and individual flowers can differ markedly in their dimensions, shapes and accessibility to pollinators, blooming time and synchronization with neighbouring flowers, and allocation of resources for attracting pollinators and setting seed (Wyatt 1982; Diggle 2003). These differences can in turn lead to variation within inflorescences in pollinator visitation (Goldingay and Whelan 1993; Paton 1993), level of outcrossing (Barrett et al. 1994) and reproductive success (Diggle 2003). Comparisons between pollinators' preferences for specific regions within plants and floral units may therefore constitute an important aspect of pollinator complementarity (Blüthgen and Klein 2011).

The contribution of a pollinator visit to fruit or seed set also varies considerably between pollinator species and is affected by diverse aspects such as pollinator morphology, size and foraging behaviour on the focal plant (e.g. Sahli and Conner 2007). The issue is even more complex in self-incompatible plant species, in which fruit/seed set depends upon the deposition of compatible cross pollen from other plant individuals. In such species, frequent switching of the pollinator between plant individuals is considered beneficial as in prolonged visitation of the same plant, the pollinator can continue to forage and deplete the rewards long after having deposited all its foreign pollen (Andersson 1988). Previous visitors may also affect the single visit contribution to fruit/seed set of a new visitor, due to gradual depletion of the flower's pollen and nectar; this may either increase fruit/seed set (due to higher cross/self pollen ratios on stigmas, Rodet et al. 1998) or decrease it (due to a shorter visit associated with collection of smaller reward, Hingston and McQuillan 1999). Thus, detailed measurements of pollinators' contributions to fruit/seed set following multiple visits (beyond the simple single-visit experiments) are required to obtain a more accurate and valid estimate of their pollination services.

In order to demonstrate that pollinators provide complementing pollination services, contrasting patterns in their contribution to pollination across time, space or phenological conditions need to be established. Therefore, detailed measurements of each pollinator's visit frequencies and single-visit pollination efficien- 
cies are required. In the current study, we aim to investigate these two components in the context of crop pollination. We examined the fine-scale spatiotemporal patterns of visitation and the contribution to seed set of three locally common bee species (commercially managed honeybees and two wild bee species) in Israel. As our plant model, we selected confection (non-oil) sunflower, Helianthus annuus L., a self-incompatible crop that is fully dependent upon insect visitation to set seed (Dag et al. 2002), whose family (Asteraceae) is generously represented in the Israeli wild flora (Feinbrun-Dothan and Danin 1998). Our research questions were (1) How does fine-scale temporal and phenological variability affect bee visitation? (2) Does temporal and phenological variation in visitation activity, if exists, show complementary trends between bee species? (3) Are there differences between the dominant visitor species in contribution to seed set? If such differences exist, are they linked to morphological or behavioural differences between species?

\section{MATERIALS AND METHODS}

\subsection{Study system}

The research was carried out in 2009-2012 in the Judean Foothills, a Mediterranean agro-natural ecosystem in central Israel $\left(31.6-31.9^{\circ} \mathrm{N}: 34.7-35.0^{\circ} \mathrm{E}\right.$, 60-280 m a.s.1.). All data were collected on standardized weather conditions (sunny days, wind velocity $<5 \mathrm{~m} / \mathrm{s}$, temperature $>18{ }^{\circ} \mathrm{C}$ ). The wild bee fauna in the region is diverse and consists mostly of small- to medium-sized solitary bees (unpublished data). Honeybees, Apis mellifera Linnaeus 1758, are commonly managed for crop pollination and honey production, in hives located around and within fields and orchards, but feral honeybees are absent due to Varroa mites.

Confection sunflower is commonly grown in the region under crop rotation regime, in drip irrigation. Fields are sown in March at a density of 2-3 plants/ $\mathrm{m}^{2}$ and reach bloom in May. Honeybee hives are placed in the fields at the start of bloom at typical densities of 1 hive/6,000-7,000 $\mathrm{m}^{2}$. During bloom, many fields are sprayed with triadimenol, a fungicide used to combat mildew (considered relatively nonhazardous for honeybees, Tew 1998). The seeds are harvested in August-September, when the plants have completely dried out.

A confection sunflower capitulum, or head, typically contains an average of 1,000 florets and flowers for 6-10 days, starting from the periphery and advancing towards the centre. Each day, two to four new whorls of florets open; on their first day, florets are in the male stage and from the second day onwards in the female stage (Free 1993; Ben-porat and Massad 1994).

\subsection{Data collection}

\subsubsection{Sunflower bloom measurements}

Sunflower bloom data at the field and plant level was collected concomitant with flower-visitor observations. At the field level, on each plot at each observation date, we counted all the unopened, flowering and wilted heads in each of four nonadjacent rows, at least 15 heads per row. The field bloom stage (ranging from -1 to 1 ) and field bloom percentage were calculated as (no. of wilted headsno. of unopened heads)/(no. of total heads) and $100 \times$ (no. of flowering heads) $/($ no. of total heads), respectively. At the plant level, head sizes were classified as small (diameter $<11 \mathrm{~cm})$, medium $(11 \leq$ $d<15 \mathrm{~cm})$ or large $(d \geq 15 \mathrm{~cm})$. Head bloom stages were ranked on a continuous, linear scale from 0 to 4 , based on the position of the freshly open floret whorls, as follows: 0 - all florets are before bloom; 1 - outer third of radius in bloom; 2-intermediate third of radius in bloom; 3-inner third of radius in bloom; and 4 -all florets are withered; intermediate stages were assigned with fractional numbers.

\subsubsection{Flower-visitor observations}

Visitation counts of honeybees and wild bees were collected in two datasets. In the main dataset, visitation was observed in 29 fields -13 in 2009 and 16 in 2010 - all at a minimum distance of $1 \mathrm{~km}$ from each other; observed cultivars were the principal ones grown in the region (DY3, Shemesh and Shelly). To obtain a broad spectrum of pollinator communities of differing abundance and diversity, we selected fields with different surrounding land use 
types, i.e. percent natural and semi-natural area (ca. $0-60 \%$ in $1,000-\mathrm{m}$ radii around fields), vs. agricultural and built area (ca. 20-90\% in 1,000-m radii around fields). Ten fields bordered an area with the typical natural habitat of shrubland (batha) or herbaceous vegetation, along parts of their perimeter; another 11 fields bordered different land use types (e.g. rural settlements, agriculture fields) but contained some patches or strips $(<20 \mathrm{~m}$ in width) of wild vegetation in between. Field size was $200,000 \pm 16,000 \mathrm{~m}^{2}$ (mean $\pm \mathrm{SE}$ ). In each field, a $25 \times 25-\mathrm{m}$ plot was marked at the field edge; in nine fields, an additional $25 \times 25$-m plot was marked at the interior of the field, $80-110 \mathrm{~m}$ from the edge. Each plot was observed on one to two different dates. In each plot on each date, 40 randomly chosen heads were observed between 0730 and 1130 hours and another randomly chosen 40 were observed between 1130 and 1530 hours, thus covering the main daily period of activity for the majority of bee species. For each head, we recorded the head size and bloom stage and the number of visits per each bee species encountered during $30 \mathrm{~s}$ of observation. In order to validate species identifications of observed bee visitors, after each round of observation, we netted wild bees for 10-15 $\mathrm{min}$ in each plot.

To increase our sample size of wild bee visits and to obtain detailed patterns of hourly visitation rates along all activity hours of the day, we included a second dataset consisting of hourly observations conducted between 0700 and 1900 hours in 20102012. We observed 4 fields of the DY3 cultivar (2 fields of the former dataset and 2 novel fields), on 12 different days in total. On each sampling day, every $60 \mathrm{~min}$, we randomly selected 12 heads for observation, at a distance of 5-25 $\mathrm{m}$ from the field edge. For each head, we recorded the head size and bloom stage and the number of visits per each bee species encountered during $1 \mathrm{~min}$ of observation. Limited collection of representative specimens of wild bees encountered in the observations was done between observations to ensure correct species identification.

\subsubsection{Pollination experiments}

Experiments were conducted on cultivar DY3, in three sites, in 2010-2012. Heads were covered with $30 \times 40-\mathrm{cm}$ muslin bags prior to anthesis, to exclude visitors. When reaching a bloom stage between 1 and 2.5, heads were exposed to one to eight visits (whether simultaneous or sequential) of honeybees and/or wild bees and rebagged. For each visited head, we recorded the number of visits per bee species; in heads exposed to a single bee visit, we also recorded the sector of the head visited by the bee and measured the visit duration. Many visits were terminated after just a few seconds, with the bee probing little if any florets; since functionally these types of visits are expected to differ from longer visits, we classified bee visits as either forage visits (lasting $\geq 20 \mathrm{~s}$ ) or rejection visits $(\leq 10 \mathrm{~s})$. Control pollination treatments included bagged heads excluded from pollinators, openpollinated heads, artificially cross-pollinated heads and open-pollinated heads artificially supplemented with cross pollen. In the latter two treatments, cross pollen was applied to all female florets with a delicate brush, for three times in 2-day intervals, matching the blooming progression of the head.

About 60 days post-anthesis, heads were harvested and the percentage of seed set was determined. In each head, all the achenes were extracted and transferred to a bowl, out of which we randomly sampled 100 achenes. Sampled achenes were opened and checked for the presence of developed seeds. Since seed set in heads exposed to a single bee visit was found to be very low and similar to the pollinator-excluded control, additional comparisons were required to test the contribution of the different bee species to seed set. For honeybees, we also tested heads exposed to multiple visits (two to eight). Visitation rates of wild bees were too low to allow multiple visit testing; instead, we analysed seed set within each of 19 heads exposed to a single wild bee visit by comparing the seed set percentage in the sector visited by the bee to the seed set in the remaining sector. In these heads, $100 \%$ of achenes were checked for the presence of developed seeds.

\subsection{Statistical analysis}

All analyses were performed using IBM SPSS Statistics 20, Release 20.0.0 (SPSS Inc., Chicago, 2011).

Visitation patterns Observations conducted between 0730 and 1530 hours from both visitation datasets 
were combined to test the effects of spatial, temporal and phenological variability on bee visitation. Differing durations of individual observations (30 s vs. $1 \mathrm{~min}$ ) between datasets are not expected to cause bias, as in ca. $70 \%$ of recorded visits the bees were already foraging on the head at the start of the observation. We generated a generalized linear mixed model (GLMM) to test the effects of temporal (time along the season and along the day) and phenological (stage and percentage of field bloom and stage and size of head bloom) variability on bee visitation. The model was generated with a binomial distribution and a logit link function and included field and head within field as subjects, field as a random variable, bee species as repeated measures and presence/ absence of a visit as the dependent binomial variable. Predictor (fixed) variables included were bee species, head size category (small/medium/large) and head bloom stage category $(0.5 / 1 / 1.5 / 2 / 2.5 / 3)$ as factors; field bloom stage, field bloom percentage, date (number of days since May 1, regardless of year) and hour as covariates; and interaction terms between bee species and each of the other predictors. Our assumption was that significant interactions between bee species and other predictors indicate the existence of spatiotemporal or phenological differences in visitation patterns between species, possibly leading to complementary visitation patterns. To test the effect of spatial variability, i.e. location within the field (edge vs. interior) on bee visitation, we generated a subset model with only the nine fields where the field interior was sampled, in which we included all the predictor variables of the overall model, plus location within field as a factor. Further subset models were generated to test for honeybee competition/facilitation effects on wild bees, with visitation of a single wild bee species as the dependent variable, and the predictor variables of the overall model plus honeybee visitation as a factor. For all models, insignificant effects were removed from the final model in a stepwise manner. Tests of fixed effects and coefficients were run with robust covariances, and degrees of freedom were computed using the Satterthwaite approximation.

Pollination experiments Percent seed set was compared between treatments using one-way ANOVA or an independent samples $t$ test; when comparing single visit and closed control treatments, data was log transformed. In 19 of the heads visited by wild bees, seed set was compared between visited and nonvisited (control) head sectors using a sign test. The effects of the number and duration of bee visits on seed set were each tested in simple linear regression models, with data $\log$ transformed. In heads exposed to one to eight honeybee forage visits, the average contribution to seed set of a single honeybee visit was calculated for each head as (\% seed set-median \% seed set of the closed control)/(number of visits). The effect of the number of visits on the average contribution per visit was tested by linear regression with data log transformed.

\section{RESULTS}

\subsection{Flower visitation}

In total, 6,972 sunflower heads were observed for $69 \mathrm{~h}$, across 31 different sites. Three species of bees were observed frequently on the heads: honeybees (A. mellifera, 5,266 visits on 3,440 heads, $92.8 \%$ of all recorded bee visits, observed at all sites); Lasioglossum malachurum (Kirby 1802), a small (intertegular (IT) span $1.6 \mathrm{~mm}$ ) annually social bee (151 visits on 130 heads, $2.7 \%$ of all bee visits, 19 sites); and Lasioglossum politum atomarium (Morawitz 1876), a tiny (IT span $0.8 \mathrm{~mm}$ ) social bee (178 visits on 124 heads, $3.1 \%$ of all bee visits, 9 sites); other species were rare $(<10$ visits per single morphospecies; in total, 80 visits on 76 heads, $1.4 \%$ of all bee visits, 22 sites - including some dubious identifications which may in fact belong to one of the two common wild species). Averaged among all 31 sites, visit frequencies (mean $\pm \mathrm{SE}$ ) were $0.37 \pm 0.02$ visits $/ \mathrm{min}$ for $A$. mellifera, $0.008 \pm 0.002 \mathrm{visits} / \mathrm{min}$ for $L$. malachurum and $0.018 \pm 0.011$ visits $/ \mathrm{min}$ for $L$. politum. Three hundred thirty-seven wild bee individuals were netted from 30 different bee species. Of these, eight spp. (269 individuals) were Lasioglossum spp. (polylectic but with known preference for Asteraceae, Polidori et al. 2010), and four spp. are known as Asteraceae specialists (Osmia signata, Osmia dives, 
Megachile albisecta and Colletes similis; 20 individuals in total).

The three common bee species greatly differed in their foraging behaviour and foraging type (pollen and/or nectar). Honeybees foraged mostly for nectar ( $>99 \%$ of all visits observed). Some honeybees ( $24 \%$ of all visits) also collected pollen incidentally while nectar foraging, as evident by the orange pollen pellets in their corbiculae; deliberate scrabbling for pollen was rare $(<1 \%$ of all visits $) . L$. malachurum foraged mainly for pollen $(81 \%$ of all visits); activity shifted gradually from pollen collection in the early morning to nectar collection in the afternoon. L. politum exhibited an opposite trend, foraging mainly for nectar ( $96 \%$ of all visits). Interactions between species were also observed. Following an encounter between a honeybee and a wild bee on a head, the wild bee (but not the honeybee) often abandoned the foraged head.

Observations on visitors showed that contact with the florets' sexual organs, crucial for seed set, differed between bee species and foraging activities. Honeybees often contacted the stigmas, and many workers were heavily dusted with pollen. The two wild bee species only rarely contacted the stigmas, mostly when collecting pollen or walking among florets. Pollen-collecting wild bees usually kept their bodies relatively free of pollen outside the scopa and touched the stigmas only with their front legs and mouthparts.

The GLMM analysis of temporal and phenological visitation patterns yielded two alternative similar models, which differ in the inclusion of either one of two correlated variables-field bloom stage and date - and have otherwise the same set of significant variables and a similar overall model fit (Table I). The models show significant effects of temporal and floral variability on bee visitation, including some differential effects between bee species (Table I and Online Resource 1). On the other hand, the spatial subset model showed no effect of spatial variability (location within field); however, wild bees were absent or very rare in most of the nine fields in which we sampled both the edge and the interior.
The wild bee subset models did not show any effect of honeybee activity on wild bees' visitation patterns. Overall, significant effects on bee visitation at the field level were as follows: temporally, bee visitation decreased along the day, but increased along the season; phenologically, bee visitation increased with the blooming progression of the field (Table I). The inclusion of either date or field bloom stage, but not both, yielded similarly successful models (Table I); these two variables were correlated $(r=0.42, P<0.001)$. The other phenological predictor at the field level, field bloom percentage, did not affect bee visitation. At the plant level, bee visitation was affected phenologically by both head size and bloom stage; visitation was higher in intermediate vs. early and late bloom stages and on medium and large vs. small heads.

Significant differences between bee species were seen in temporal and phenological effects on visitation, namely hour and head bloom stage (Table I and Figures 1 and 2); other interactions were insignificant. Temporally, visitation rates of both Lasioglossum species showed a generally decaying activity along the day, with a bimodal pattern of a major peak in the morning and a lower peak in the afternoon. Honeybee activity, on the other hand, was relatively constant during most daylight hours (Figure 1). Phenologically, honeybees were most common on intermediate bloom stages $(1-1.5)$ and least common on the latest stage (3); L. malachurum was most common on early stages $(0.5-1.5)$ and least common on the latest stages (2.5-3) and $L$. politum visited all stages at similar proportions (Figure 2). Significant interaction between head bloom stage and bee species was also obtained when we divided the bloom stage range into only three discrete categories.

\subsection{Seed set}

Seed set data was collected for honeybees and L. malachurum; L. politum visits were too rare in the experimental sites to be included in the pollination experiments. Heads exposed to one to two honeybee rejection visits, a single forage visit of a honeybee or a single forage 
Table I. Results of the GLMM analysis for overall bee visitation on sunflowers. Models 1 and 2 are similar and differ in the inclusion of either field bloom stage or date as covariates, respectively.

\begin{tabular}{|c|c|c|c|c|c|c|c|c|c|}
\hline & \multirow[t]{2}{*}{ Effect type } & \multicolumn{4}{|c|}{ Model 1} & \multicolumn{4}{|c|}{ Model 2} \\
\hline & & $F$ & df1 & df2 & Sig. & $F$ & df1 & df2 & Sig. \\
\hline corrected model & & 296.3 & 23 & 110 & 0.000 & 326.6 & 23 & 101 & 0.000 \\
\hline \multicolumn{10}{|l|}{ Factors } \\
\hline Species & & 4.1 & 2 & 8 & 0.062 & 4.1 & 2 & 7 & 0.062 \\
\hline Head size & phen & 25.7 & 2 & 278 & 0.000 & 30.1 & 2 & 357 & 0.000 \\
\hline Head bloom stage & phen & 15.0 & 5 & 83 & 0.000 & 13.2 & 5 & 92 & 0.000 \\
\hline \multicolumn{10}{|l|}{ Covariates } \\
\hline Field bloom stage/date & phen/temp & 25.5 & 1 & 241 & 0.000 & 46.5 & 1 & 762 & 0.000 \\
\hline Hour & temp & 19.9 & 1 & 16 & 0.000 & 18.8 & 1 & 15 & 0.001 \\
\hline \multicolumn{10}{|l|}{ Interactions } \\
\hline Species $\times$ head bloom stage & phen & 14.9 & 10 & 100 & 0.000 & 15.2 & 10 & 87 & 0.000 \\
\hline Species $\times$ hour & temp & 29.7 & 2 & 66 & 0.000 & 29.4 & 2 & 65 & 0.000 \\
\hline
\end{tabular}

$\mathrm{AICc}=120,524$ and 120,603 ; accuracy $=85.8$ and $85.9 \%$

phen phenological, temp temporal

visit of L. malachurum set $0.9,3.3$ and $1.5 \%$ seeds, respectively (median values; ranges 0.0 24.2, 0.0-45.0, 0.0-32.8; $N=13,37,29)$. These treatments did not differ significantly from each other nor from the pollinator-excluded control, which yielded $1.1 \%$ seed set (range 0.0-23.8,

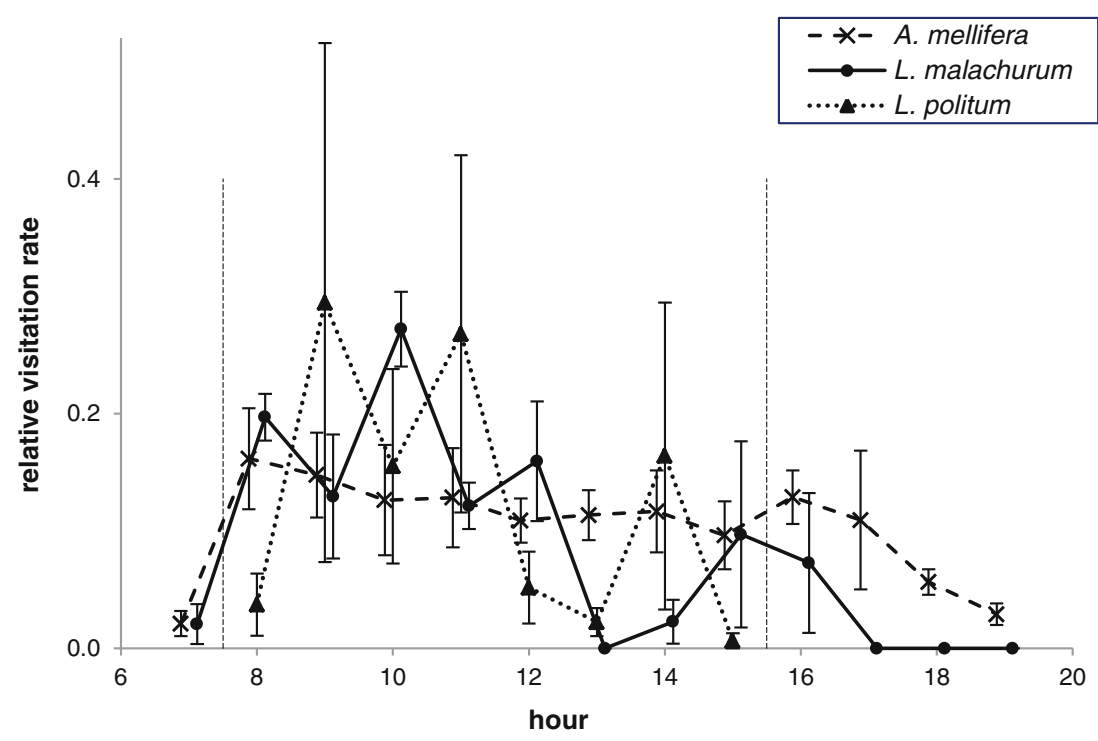

Figure 1. Relative hourly visitation rates on confection sunflower. Each data point represents a mean \pm SE of three to six fields. Dashed vertical lines indicate the period 0730-1530 hours included in the GLMM model. For each species, the visitation rates between these hours add up to 1.0. For L. politum, data is available only for these hours, as it was rare in the fields where we conducted full-day hourly measurements. 


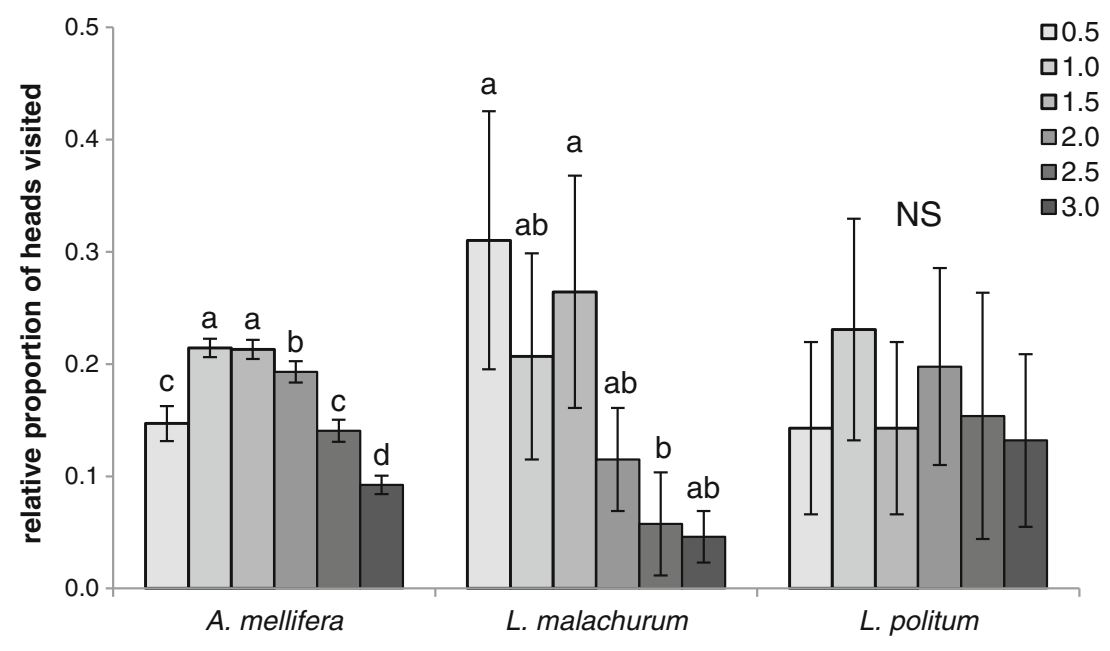

Figure 2. Relative proportions of heads visited by each bee species at each head bloom stage (mean $\pm \mathrm{SE}$ ), based on the estimated means of the GLMM model. For each species, all columns add up to 1.0. For each species, different letters indicate significant differences.

$N=33$ ) (one-way ANOVA, $F_{3}, \quad 108=2.2, P=$ $0.09)$. Seed set in head sectors visited by $L$. malachurum did not differ from the seed set in the unvisited sectors of the same heads (difference range (visit-control): -9.9 to $6.8 \%$, median $0.0 \%, N=19$; sign test, $P=1.0$ ). Artificially crossed, open-pollinated and pollen-supplemented heads yielded 51, 62 and $62 \%$ seed set, respectively $(N=14,33,15)$; pollen supplementation of open-pollinated heads did not result in higher seed set (independent samples $t$ test, $t=1.2, P>0.2$ ).

In heads exposed to a single bee visit, the median duration of a forage visit was $334 \mathrm{~s}$ for honeybees and $80 \mathrm{~s}$ for L. malachurum (longest visits lasted 15 and $26 \mathrm{~min}$, respectively). Seed set percentage was positively affected by the visit duration of honeybees (though coefficient values were low), but not of L. malachurum (linear regression, $F=5.0, N=43, P=0.03$, adjusted (adj.) $R^{2}=0.09$ for honeybees; $F=0.7, N=26, P=0.41$, adj. $R^{2}=-0.01$ for L. malachurum; Figure 3). Seed set percentage also increased with increasing number of honeybee forage visits (linear regression, $F=54.3, N=172, P<0.001$, adj. $R^{2}=0.24$; Figure 4). Averaged among heads, each honeybee forage visit contributed a median of $3.1 \%$ increase in seed set (mean $6.2 \%$, range $(-1.1$ to $43.9 \%, N=79)$. Contribution per visit did not change significantly with increasing visits (linear regression, $P>0.5$, adj. $R^{2}<0.0$ ).

\section{DISCUSSION}

\subsection{Bee visitation patterns}

Visitation patterns of the three dominant bee species were affected by a range of temporal and floral factors at both field and plant scales. The presence of seasonal, hourly and bloom stage effects on bee visitation patterns at the field level indicates the importance of the blooming phenology of sunflowers and surrounding wild vegetation. Increasing bee activity on sunflowers along the season or with increasing field bloom stage can be attributed to the simultaneous decrease in abundance of wildflowers from late spring to early summer (London-Shafir et al. 2003) and to the concurrent growth of the honeybee colonies. The decreasing activity pattern along the day of the two Lasioglossum species is probably related to their attraction to the pollen of Asteraceae spp. (Polidori et al. 2010), which is presented in the 
a
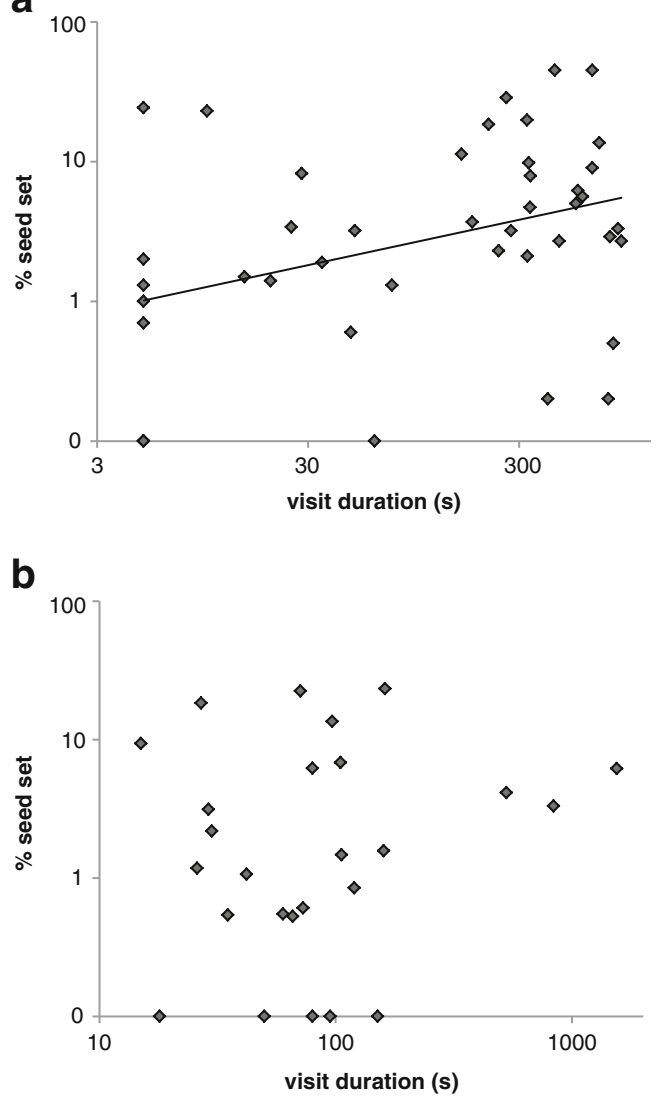

Figure 3. The effect of visit duration on seed set percentage in DY3 heads exposed to a single visit of a honeybee (a) or L. malachurum (b).

sunflowers mainly in the early morning hours, and removed by the honeybees by ca. 1000 hours (Free 1993 and personal observation). On the other hand, a significant portion of honeybee workers are averted by sunflower pollen (Free 1993) and may prefer to forage later during the day when it is scarce, resulting in a more stable overall daily activity pattern of honeybees compared to the two wild species.

Direct phenological effects on bee activity were seen mostly at the plant level, as reflected by both head size and head bloom stage. These two variables are correlated, since the head grows in diameter as its bloom progresses (Spearman's $\rho=0.48, P<0.001)$. However, the

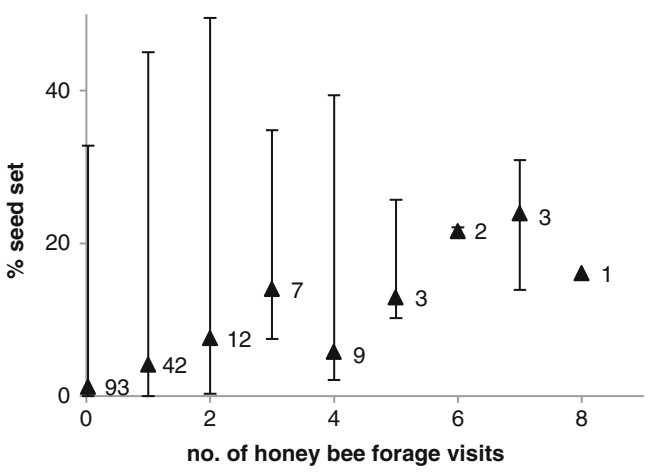

Figure 4. Percent seed set (median \pm range) in DY3 heads exposed to zero to eight honeybee forage visits. Sample sizes are noted next to each data point.

relationship between each variable and bee visitation showed different patterns, i.e. preference for larger heads vs. intermediate and early bloom stages. Nonetheless, both of these patterns can be similarly interpreted as a general preference for heads with larger reward and/or advertisement (Neff and Simpson 1990; Sapir 2009). Differences between bee species in the effects of head bloom stage can be attributed to their morphologies and foraging habits. Bloom stages of $0.5-1$ have the highest numbers of pollen-presenting male florets, whereas stages of 1-1.5 have the highest number of nectarcontaining (male and young female) florets. This difference could explain why $L$. malachurum (which foraged mainly for pollen) was attracted to earlier stages compared to honeybees (which foraged mainly for nectar). The lack of a significant bloom stage preference pattern in L. politum is probably related to the species' small dimensions; tiny bees have lower demands for pollen and nectar (Müller et al. 2006) and are likely to be contented even with heads in suboptimal states.

Overall, bee species' visitation patterns were similarly affected by most predictor variables and can be considered mostly redundant. Differences between species were seen in finescale predictors (hour and head bloom stage) and were related to their foraging habits, which dictate different flowering phenological prefer- 
ences. Contrasting, i.e. complementing trends were hardly seen between different species; rather, the major differences were seen in sensitivity of some species but not others, to a certain predictor (i.e. wild bees vs. honeybees in the effect of hour; honeybees and L. malachurum vs. L. politum in the effect of bloom stage). The preference of the main visitor species, the honeybee, for intermediate bloom stages may be partially compensated by the increased visitation of early and late bloom stages by $L$. malachurum and L. politum, respectively; however, the low visitation rates of these species compared to that of honeybees weaken this effect. Nonetheless, in a possible event of a sharp decrease in honeybee availability, phenological complementarity could play an increasing role in this system.

\subsection{Seed set}

The combined results from the seed set experiments demonstrate a significant contribution of honeybees but not of L. malachurum, to confection sunflower pollination. We attribute the differences in contribution to pollination between the two species to their sizes and foraging behaviours (Sahli and Conner 2007; Westerkamp 1996). Honeybees are mediumsized bees that forage on sunflower primarily for nectar. Accordingly, they forage on both female and male florets, and when doing so, they make significant contact with the stigmas. Because honeybees are often averted by sunflower pollen, many workers are heavily dusted with pollen which they do not pack into their corbiculae. On the other hand, L. malachurum is a small bee that forages on sunflower mainly for pollen. Accordingly, it forages mainly on male florets, makes less contact with the stigmas and keeps its body relatively clean of pollen (outside the scopa). Although we could not test the contribution of L. politum to seed set, its body size and foraging behaviour (rarely contacting the stigmas) strongly suggest that like $L$. malachurum, it does not have a significant contribution to confection sunflower pollination. It seems that confection sunflowers in particular require larger bodied pollinators to match the wider and longer florets characteristic of these cultivars (Ben-porat and Massad 1994). Apart from the managed honeybees, such pollinators rarely visited sunflowers in our study region.

Seed set in heads subject to single visit and closed control treatments showed right-skewed distributions and considerable variation. This indicates large variation in the degree of selfincompatibility between individual plants, allowing different rates of spontaneous selfpollination, and in the seed set contribution of a honeybee forage visit. Our results suggest that a single forage visit of a honeybee can contribute as much as $20 \%$ of the total head seed set or none at all. This large variation can be attributed to difference between workers in the foraging behaviour on the sunflower head (including the visit duration and the type of florets foraged-male vs. female) and in the amount of pollen on the bee's body at the start of the visit. From the regression of honeybee visit durations against seed set rates, it appears that contrary to expectations, even in extremely long visits, lingering on the same head still continues to increase seed set. Although most pollen deposition and seed set contribution probably occur at the start of the visit, continued movement among the florets can still contribute to seed set by exposing new stigmatic surfaces which were covered by self pollen and redistributing previously deposited cross pollen (Greenleaf and Kremen 2006). However, visit duration could only explain ca. $10 \%$ of the variation in seed set contribution of honeybee visits, and other factors are probably more important.

Despite the possible bias in using bagged heads in which large quantities of pollen and nectar are accumulated compared to openpollinated heads (Neff and Simpson 1990), the average seed set contribution of a honeybee visit did not change with increasing numbers of visits that gradually deplete the pollen and nectar in the head. Even when considering the shorter visit duration on exposed vs. bagged heads (ratio of 1:5.5, unpublished data), we 
estimate that an average honeybee forage visit contributes at least $1.2-1.5 \%$ net increase in seed set to open-pollinated heads (see Figure $3 \mathrm{a}$ ). On each day, $\leq 30 \%$ of florets on a head open, hence $\leq 20$ forage visits per day would be sufficient to insure a maximal seed set (60-80 \%, Ben-porat and Massad 1994; Dag et al. 2002). Previous studies have specified much higher visitation requirements for sunflowers (e.g. an average of 0.25 bees per head at any single time, equivalent to 75 visits per head per day, Ben-porat and Massad 1994). However, these estimations originated most probably from oil-producing cultivars and were based on correlations between bee counts and seed yield at the field level (Free 1993 and references therein), rather than direct manipulations of individual plants as done here. Our calculations show that under the current pollination management regimes in our system, DY3 sunflower fields are overloaded with honeybee hives, causing their visitation rates to exceed the pollination requirement by a factor of at least 5 .

\subsection{Conclusions}

The dominant bee species in our crop system differed in their visitation patterns; daily and inter-plant trends were present in some species but not in others. In particular, differential visitation patterns within floral units such as the composite (Asteraceae) capitulum were demonstrated between the species examined and may be an important underlying mechanism facilitating complementarity in more diverse systems. These findings demonstrate the importance of detailed assessments of pollinators' foraging patterns along multiple spatiotemporal scales, when estimating their contribution to pollination and its stability. However, unmanaged pollinators were relatively rare on sunflowers in our system, despite their great abundance and diversity in the region (unpublished data), and the two main wild visitor species largely overlapped the honeybee visitation niche and seemed to lack a significant contribution to sunflower seed set. The rarity of unmanaged pollinators also suggests that interspecific interactions during sunflower visita- tion are infrequent in our system, and the observed interactions show no evidence of change in honeybee visit behaviour. Therefore, sunflower seed set could not benefit much from the presence of unmanaged pollinators or from pollinator complementarity. Other studies have shown significant unmanaged pollinator contributions to sunflower visitation and/or seed set (e.g. Parker 1981; Greenleaf and Kremen 2006; Carvalheiro et al. 2011; Sáez et al. 2012). Our system thus represents the lower end of a scale of sunflower pollination by unmanaged pollinators, which could be attributed to specific characteristics of the landscape (e.g. high availability of wild bloom) and the bee community (e.g. preponderance of small-sized bees), the specific cultivars studied and/or to the honeybee management in the region. As for the latter, we found that honeybee densities greatly exceed the pollination requirements of sunflower fields in our study system. This overstocking may negatively affect surrounding habitats and the native bee fauna, especially in highly fragmented and semi-arid systems, like ours (Shavit et al. 2009). Hence, a decrease in hive density in sunflower fields may increase the sustainability of the study system by enhancing wild pollinator activity around and within fields without jeopardising crop production.

\section{ACKNOWLEDGMENTS}

We thank Gillat Bartana, Lihi Gal, Tahl Paran and Itai Rozen for their help in field data collection; Amots Dafni, Dan Eisikowitch, Harmen P. Hendriksma and Yiftach Vaknin for valuable information and advice; and Alain Pauly (Brussels, Belgium) for the identification of halictid bees. This research was funded in part by the Israel Ministry of Agriculture Research Grant No. 8240112-08, the Israel Science Foundation Research Grant No. 919/09 and the Ministry for Science and Culture of Lower Saxony Grant No. 11-76-251-99-06/08.

Les abeilles sauvages viennent-elles en complément de la pollinisation, effectuée par les abeilles (Apis mellifera), du tournesol de confiserie en Israël?

Pollinisation / Helianthus annuus / Lasioglossum malachurum / Lasioglossum politum / 
complémentarité des pollinisateurs / variation intrainflorescence

Ergänzen Wildbienen die Bestäubung durch Honigbienen bei Sonnenblumen in Israel?

\section{Kulturpflanzenbestäubung / Lasioglossum malachurum / Lasioglossum politum / Ergänzung von Bestäubungsleistungen / Intra-Infloreszenz- Variationen}

\section{REFERENCES}

Aizen, M.A., Garibaldi, L.A., Cunningham, S.A., Klein, A.M. (2008) Long-term global trends in crop yield and production reveal no current pollination shortage but increasing pollinator dependency. Curr. Biol. $18,1-4$

Albrecht, M., Schmid, B., Hautier, Y., Müller, C.B. (2012) Diverse pollinator communities enhance plant reproductive success. Proc. R. Soc. B 279, $4848-4852$

Andersson, S. (1988) Size-dependent pollination efficiency in Anchusa officinalis (Boraginaceae): causes and consequences. Oecologia 76, 125-130

Barrett, S.C.H., Harder, L.D., Cole, W.W. (1994) Effects of flower number and position on self-fertilization in experimental populations of Eichhornia paniculata (Pontederiaceae). Funct. Ecol. 8, 526-535

Ben-Porat, A., Massad, Y. (1994) Honey bee behaviour in a D.Y.3 sunflower field. Gan Sade Vameshek 2, 14-23 (in Hebrew)

Biesmeijer, J.C., Roberts, S.P.M., Reemer, M., Ohlemuller, R., Edwards, M., et al. (2006) Parallel declines in pollinators and insect pollinated plants in Britain and the Netherlands. Science 313, 351-354

Blüthgen, N., Klein, A.M. (2011) Functional complementarity and specialisation: the role of biodiversity in plant-pollinator interactions. Basic Appl. Ecol. 12, 282-291

Brittain, C., Kremen, C., Klein, A.M. (2012) Biodiversity buffers pollination from changes in environmental conditions. Global Change Biol. 19, 540-547

Carvalheiro, L.G., Veldtman, R., Shenkute, A.G., Tesfay, G.B., Pirk, C.W.W., et al. (2011) Natural and withinfarmland biodiversity enhances crop productivity. Ecol. Lett. 14, 251-259

Chagnon, M., Gingras, J., De Oliveira, D. (1993) Complementary aspects of strawberry pollination by honey and indigenous bees (Hymenoptera). J. Econ. Entomol. 86, 416-420

Dag, A., Lior, E., Afik, O. (2002) Pollination of confection sunflowers (Helianthus annuus L.) by honey bees (Apis mellifera L.). Am. Bee J 142, 443-445
Diggle, P.K. (2003) Architectural effects on floral form and function: a review. In: Stuessy, T.F., Mayer, V., Horandl, E. (eds.) Deep morphology: toward a renaissance of morphology in plant systematics, pp. 63-80. A.R.G. Gantner Verlag, Ruggell

Feinbrun-Dothan, N., Danin, A. (1998) Analytical Flora of Eretz-Israel, 2nd edn. CANA, Jerusalem

Free, J.B. (1993) Insect Pollination of Crops, 2nd edn. Academic Press, London

Garibaldi, L.A., Steffan-Dewenter, I., Kremen, C., Morales, J.M., Bommarco, R., et al. (2011) Stability of pollination services decreases with isolation from natural areas despite honey bee visits. Ecol. Lett. 14, 1062-1072

Goldingay, R.L., Whelan, R.J. (1993) The influence of pollinators on fruit positioning in the Australian shrub Telopea speciosissima (Proteaceae). Oikos 68, 501-509

Greenleaf, S.S., Kremen, C. (2006) Wild bees enhance honey bees' pollination of hybrid sunflower. Proc. Natl. Acad. Sci. USA 103, 13890-13895

Hingston, A.B., McQuillan, P.B. (1999) Displacement of Tasmanian native megachilid bees by the recently introduced bumblebee Bombus terrestris (Linnaeus, 1758) (Hymenoptera: Apidae). Aust. J. Zool. 47, 59-65

Hoehn, P., Tscharntke, T., Tylianakis, J.M., SteffanDewenter, I. (2008) Functional group diversity of bee pollinators increases crop yield. Proc. R. Soc. B 275, 2283-2291

Holden, C. (2006) Report warns of looming pollination crisis in North America. Science 314, 397

Kremen, C. (2005) Managing ecosystem services: what do we need to know about their ecology? Ecol. Lett. 8, 468-479

Kremen, C., Ostfeld, R.S. (2005) A call to ecologists: measuring, analyzing, and managing ecosystem services. Front. Ecol. Environ. 3, 540-548

London-Shafir, I., Shafir, S., Eisikowitch, D. (2003) Amygdalin in almond nectar and pollen-facts and possible roles. Plant Syst. Evol. 238, 87-95

Müller, A., Diener, S., Schnyder, S., Stutz, K., Sedivy, C., Dorn, S. (2006) Quantitative pollen requirements of solitary bees: implications for bee conservation and the evolution of bee-flower relationships. Biol. Conserv. 130, 604-615

Neff, J.L., Simpson, B.B. (1990) The roles of phenology and reward structure in the pollination biology of wild sunflower (Helianthus annuиs L., Asteraceae). Isr. J. Bot. 39, 197-216

Parker, F.D. (1981) How efficient are bees in pollinating sunflowers? J. Kansas Entomol. Soc. 54, 61-67

Paton, D.C. (1993) Honeybees in the Australian environment. BioScience 43, 95-103

Polidori, C., Rubichi, A., Barbieri, V., Trombino, L., Donegana, M. (2010) Floral resources and nesting 
requirements of the ground-nesting social bee, Lasioglossum malachurum (Hymenoptera: Halictidae), in a Mediterranean semiagricultural landscape. Psyche . doi:10.1155/2010/851947

Potts, S.G., Biesmeijer, J.C., Kremen, C., Neumann, P., Schweiger, O., Kunin, W.E. (2010) Global pollinator declines: trends, impacts and drivers. Trends Ecol. Evol. 25, 345-353

Richards, A.J. (2001) Does low biodiversity resulting from modern agricultural practice affect crop pollination and yield? Ann. Bot. 88, 165-172

Rodet, G., Vaissière, B.E., Brévault, T., Grossa, J.T. (1998) Status of self-pollen in bee pollination efficiency of white clover (Trifolium repens L.). Oecologia 114, 93-99

Sáez, A., Sabatino, M., Aizen, M.A. (2012) Interactive effects of large- and small-scale sources of feral honeybees for sunflower in the Argentine Pampas. Plos ONE 7, e30968. doi:10.1371/journal.pone.0030968

Sahli, H.F., Conner, J.K. (2007) Visitation, effectiveness, and efficiency of 15 genera of visitors to wild radish, Raphanus raphanistrum (Brassicaceae). Am. J. Bot. 94, 203-209
Sapir, Y. (2009) Effects of floral traits and plant genetic composition on pollinator behavior. Arthropod-Plant Interact. 3, 115-129

Shavit, O., Dafni, A., Ne'eman, G. (2009) Competition between honeybees (Apis mellifera) and native solitary bees in the Mediterranean region of Israel - implications for conservation. Isr. J. Plant Sci. 57, 171-183

Tew, J.E. (1998) Protecting honeybees from pesticides [online] http://www.aces.edu/pubs/docs/A/ANR-1088/ (accessed on 07 October 12)

Westerkamp, C. (1996) Pollen in bee-flower relations. Some considerations on melittophily. Botanica Acta 109, 325-332

Winfree, R., Kremen, C. (2009) Are ecosystem services stabilized by differences among species? A test using crop pollination. Proc. R. Soc. B 276, 229-237

Winfree, R., Williams, N.M., Dushoff, J., Kremen, C. (2007) Native bees provide insurance against ongoing honey bee losses. Ecol. Lett. 10, 1105-1113

Wyatt, R. (1982) Inflorescence architecture: how flower number, arrangement, and phenology affect pollination and fruit-set. Am. J. Bot. 69, 585-594 